\title{
Leaders
}

\section{New technology in hospital blood banking}

\author{
J K M Duguid, I M Bromilow
}

\section{Introduction}

Scientists and doctors interested in transfusion medicine have long recognised that it is difficult to establish uniform serological testing which allows for consistently accurate antibody identification and which can be adapted to suit clinical expediency.

The basis of traditional serological techniques depends on the detection of agglutination in a liquid phase. Commonly used serological techniques are affected by many variables including serum:cell ratio, ionic strength incubation time, and $\mathrm{pH}$. These may be difficult to control and standardise. To minimise these problems various new techniques have been developed. Most of these, however, still depend on interpretation of a liquid phase agglutination reaction and, particularly when the reaction is weak, reliable results are only obtained when the reaction is examined within a short space of time by an experienced person. The introduction of microplates, initially for $\mathrm{ABO}$ grouping and $\mathrm{Rh}$ typing, ${ }^{1}$ has led to the use of automated readers, ${ }^{23}$ but due to lack of an objective endpoint automated readers still have difficulty distinguishing weak agglutination reactions from negative reactions. ${ }^{4}$

The introduction of solid phase tests and column technology has helped to overcome these problems.

\section{Solid phase tests}

These depend on the immobilisation of one of the reactants so that during testing the immobilised component captures additional reactants from the liquid phase and binds them to the solid phase. ${ }^{5}$ These techniques have been successfully developed for a range of serological testing, including red cell grouping, antiglobulin testing, and antibody detection. ${ }^{4}$ They are used routinely in many laboratories but are still associated with some technical problems, particularly when used for antibody detection using antihuman globulin (AHG). The commercially available Capture-R solid phase system (Immucor Ltd; Georgia USA, distributed in the United Kingdom by Solent Diagnostics, Hants) has been shown to be sensitive for antibody detection in routine use. It can only be used to perform an anti-IgG based indirect antiglobulin test (IAT) but may offer cost and time savings in certain laboratories. ${ }^{6}$

Biotest Ltd have recently introduced a similar microplate solid phase technique and BioProducts laboratories (BPL Elstree) are also developing a solid phase enzyme linked immunosorbent assay (ELISA) based system designed for automated reading, but this system is not currently commercially available.

\section{Column technology}

Recently, interest has been generated in the use of column technology for serological testing. The original technique was based on the principle of gel filtration for separation of red blood cells from human blood. ${ }^{7}$ It was found that the principle of gel centrifugation could be modified for use as a serological tool using Sephadex G100 superfine or Sephadex G200 Superfine. Originally described by Lapierre $e t$ $a l,{ }^{8}$ the aim of this technology is to standardise red blood cell agglutination reactions, and by trapping the agglutinates, to permit simple and reliable reading.

The column consists of special microtubes containing a dextran gel matrix. Red blood cells and serum or red blood cells alone are dispensed into the microtubes, incubated if necessary, and then centrifuged under strictly controlled parameters. The gel within the microtubes acts as a sieve, unagglutinated red blood cells form a pellet at the bottom of the microtube, and agglutinated red blood cells are trapped in the gel. The gel may be neutral or contain specific reagents such as AHG or specific antibodies (anti-A, -B, anti-D, antiKell, etc). Reactions are easily visible and may be graded (fig 1). When performing the antiglobulin tests no washing of the red blood cells is required because during centrifugation, the cells are separated from their suspension medium and serum as they pass into the microtube. Red cells sensitised by IgG or complement components react with the AHG contained in the gel and the resulting agglutinates are retained within the matrix. The serum fraction does not, therefore, make contact with the AHG impregnated gel, so that neutralisation of the AHG reagent is avoided. This technique also obviates the need to use 


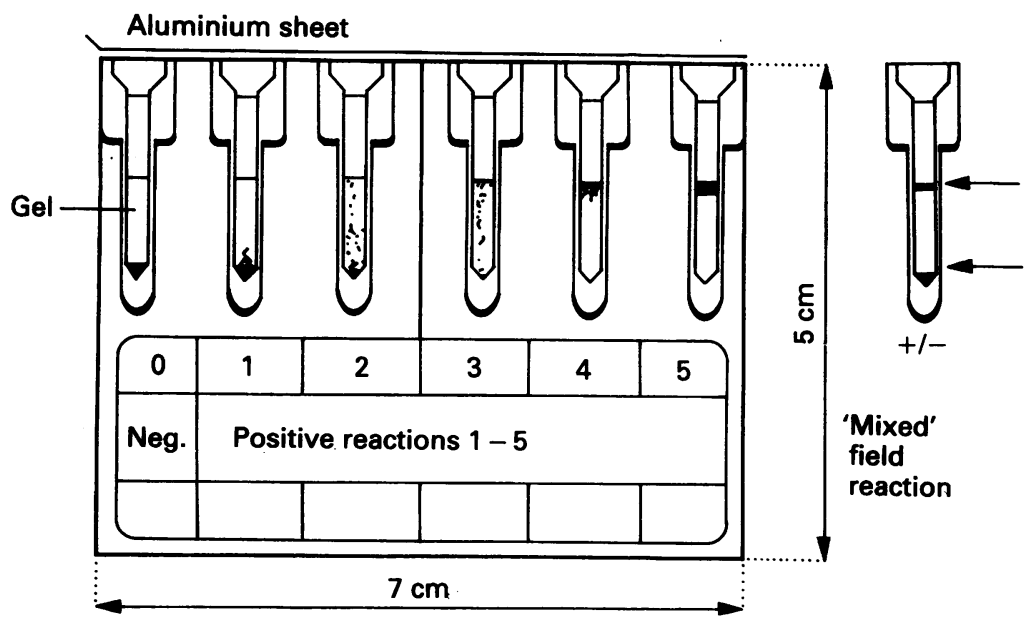

Figure 1 Reading and grading of haemagglutination in ID gel test.

pre-sensitised control cells to check negative reactions.

Neutral cards can be used as part of antibody screening for a two stage enzyme treated cell technique (fig 2 ).

Reactions using gel techniques are stable for at least $\mathbf{4 8}$ hours and have the added facility of being able to be photocopied, thereby providing a permanent record for future reference. This system is currently marketed in this country as the ID-Microtyping System (DiaMed-GB Ltd, Dalkeith, Midlothian, Scotland).

Another system is also available based on column technology-the Ortho Biovue System (Ortho Diagnostic Systems Ltd., High Wycombe, Bucks). This column contains a density gradient comprising a combination of a macromolecular density barrier and glass microspheres. The system is currently available as microtubes with columns containing AHG or neutral density gradients. Again, this system offers the ability to perform a "no wash" antiglobulin test. Preliminary reports suggest that this system is easy to use and produces stable results which can also be photocopied.

PRACTICAL APPLICATIONS OF GEL

TECHNOLOGY

Implementation of the DiaMed-ID gel system indicates that its sensitivity is superior to that of conventional tube tests without any loss of specificity. ${ }^{8-10} \mathrm{~A}$ comparison with an automated polybrene technique, a two-stage papain technique microtitre plate IAT, and a spin tube low ionic strength IAT for routine antenatal antibody screening and identification, showed an increased antibody detection rate (148 antibodies $v 95$ antibodies in 3900 samples) and a decrease in the number of non-specific enzyme only antibodies and false positive screens. Antibody titres showed an increased reaction strength and so titre scores were higher than tube IAT titres, suggesting an increased sensitivity for the gel system. ${ }^{10}$

Use in a routine hospital blood bank laboratory for red cell phenotyping ( $\mathrm{ABO}$, Rh, Kell $M$ and $N$ ), direct antiglobulin testing (DAT), antibody screening and indirect antiglobulin test compatibility testing showed that care must be taken to ensure that no greater than a $1 \%$ suspension of red blood cells is used and that problems may be encountered in patients who are DAT positive. ${ }^{11}$ It has also been shown, however, that the serological assessment of drug induced immune haemolytic anaemias is considerably improved by using the gel system. ${ }^{12}$

One study has cast doubts on the sensitivity of the antiglobulin "gel-test" for antibody detection, ${ }^{13}$ because of an apparent inability of the gel system to detect a few specially selected weak "difficult" antibodies with heterozygous cells. The clinical importance of these antibodies is unknown as they were principally used for assessment of AHG reagents and techniques. This type of testing was recognised as being a stringent sensitivity test $^{14}$ and was being compared with a "wellperformed" spin tube IAT. The relevance of this type of testing to routine work in a busy hospital or transfusion centre serology laboratory is uncertain. Available reports indicate that routine use in a busy district general hospital showed a decrease in false positive antibody detection, with an associated increased antibody identification rate (Thomas BE, Yates S. IMLS 20th Triennial Conference, September 1992, abstract 123).

\section{ADVANTAGES OF MICROTUBE SYSTEMS}

(Table 1)

Both commercially available column systems using microtubes embedded in plastic cards

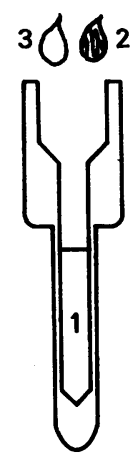

Figure 2 Use of "neutral" ID gel test for two-stage enzyme treated cell technique.
1. Neutral gel.
2. Enzyme treated red cell suspension.
3. Serum.

Table 1 Advantages and disadvantages of use of gel techniques for routine serology

\begin{tabular}{ll}
\hline Advantages & Disadvantages \\
\hline Easy to use & Commercial control \\
$\begin{array}{l}\text { Standardisation of technique } \\
\text { Stability of reactions }\end{array}$ & $\begin{array}{l}\text { Cost } \\
\text { Loss of "traditional" } \\
\text { skills }\end{array}$ \\
$\begin{array}{l}\text { Small sample volumes used } \\
\text { Tubes can be sealed easily, } \\
\text { therefore useful for "high risk" } \\
\text { samples }\end{array}$ \\
$\begin{array}{l}\text { Labour saving } \\
\text { Decreased false positive reaction }\end{array}$ \\
\hline
\end{tabular}


Table 2 Comparative costs of $A B O$ and $D$ grouping plus antibody screening by various techniques (150 samples/day)

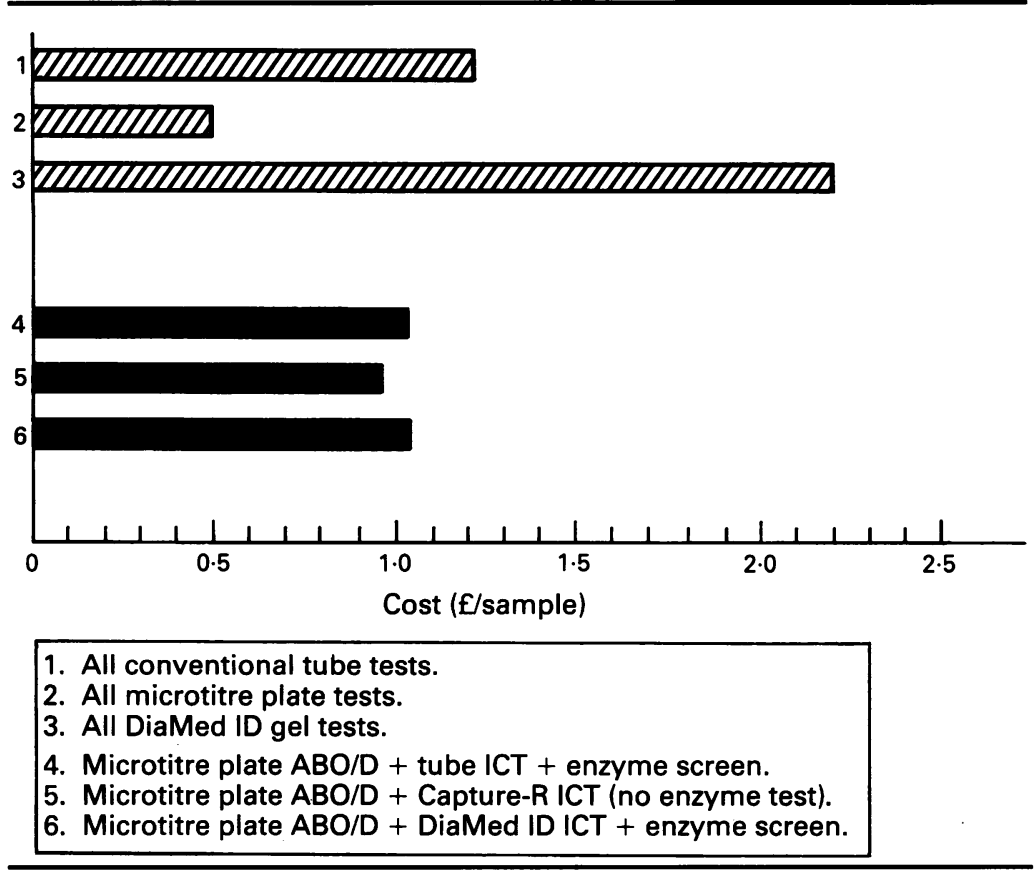

are technically easy to use. The "no-wash" IAT means that reliable testing can be performed by a wide variety of staff. Most false negative IAT results, when using conventional tube techniques, are known to be caused by inefficient cell washing or from trauma to weak red blood cell agglutinates produced by over-vigorous agitation following excessive centrifugation. These problems are eliminated when using microtube columns, allowing for the use of a broader skill-mix of staff in individual laboratories and also facilitating the use of multidisciplinary on-call staff. Both these aspects of staffing are also helped by the stability and robustness of the reactions which means that results can be checked by experienced transfusion staff.

Both systems require only small amounts of red blood cells and serum for testing (10-40 $\mu \mathrm{l})$, making them ideal for neonatal and paediatric use. The ability to photocopy results and thus keep a permanent record is also an advantage.

Microtubes can be sealed once cells and serum have been dispensed thus eliminating aerosol formation during processing and making the system particularly useful for handling "high risk" samples.

Currently $5 \%$ of United Kingdom participants in the NEQAS serology scheme use DiaMed-ID gel technology. As yet NEQAS organisers do not routinely analyse results from these laboratories as a separate group, but there is an international quality assurance scheme available to all users of gel technology organised by DiaMed. Results from this scheme are analysed and circulated regularly to all participants.

\section{DISADVANTAGES OF MICROTUBE SYSTEMS}

(Table 1)

The use of column techniques means loss of freedom of choice of reagents, particularly AHG, and there may be cost implications associated with this. All techniques are performed using a low ionic strength suspension medium. Problems known to occur with the use of this type of medium for certain antibodies may therefore remain. There have also been grave anxieties expressed at the possibility that certain laboratory skills will be lost, in particular the ability to perform a reliable spin tube IAT. It has to be recognised that this is not necessarily detrimental. Certain laboratory skills considered essential in the past have been lost because of the implementation of new technology: this has led to improved patient care.

\section{Costing}

Hospital transfusion laboratories are not considered high spenders (excluding the cost of blood and products). The cost of these commercially available systems may therefore appear prohibitive.

Perceived savings generated by decreased false positive and non-specific antibody detection or by the ability to alter staffing will obviously vary among individual laboratories. An analysis of comparative costing of $\mathrm{ABO}$ and $\mathrm{D}$ grouping and antibody screening using tubes, microplates, a gel technique, a solid phase technique and a continuous flow analyser has been performed..$^{15}$ Costs depend on the volume of samples handled, and for laboratories processing more than 25 samples/day gel cards for $\mathrm{ABO}$ and D grouping incurred significantly more expense. A combination of microplate grouping and gel antibody screening, however, was shown to cost less than conventional tube techniques (table 2).

\section{Conclusion}

It is unlikely that for serologists there will ever be a single system that encompasses cost effectiveness, ease of use, and accuracy. Transfusion laboratory practice will always be problematic due to the combination of routine and emergency work, together with sometimes unreasonable clinical and financial pressures. The introduction of gel technology, however, provides a refreshingly new approach which may, by its sheer simplicity of use and standardisation of technique, facilitate the working practices of transfusion laboratories and thus enhance the quality of the service provided to both patients and clinicians.

1 Wegmann TG, Smithies I. A simple haemagglutination system requiring small amounts of red cells and antisystem requiring small amounts of
bodies. Transfusion 1966;6:67-73:

2 Bowley AR, Gordon I, Ross DW. Computer controlled automated reading of blood groups using microplates. Med Lab Sci 1984;41:19-28.

3 Severns ML, Shoeppner SL, Cozart MJ, et al. Automated determination of $\mathrm{ABO} / \mathrm{Rh}$ in microplates. Vox Sang 1984;47:293-303.

4 Scott ML. The principles and applications of solid-phase blood group serology. Transfusion Med 1991;1:60-72.

5 Plapp FV. New techniques for compatibility testing. Arch 
Pathol Lab Med 1989;113:262-9.

6 Sangster JM, Wiggens CS. Experience with "Capture-R" solid phase antibody screening. Proceedings of the solid phase antibody screening. Proceedings of the Transfusion Society, 1991:7-8.

7 Kanura T, Kurashina S, Nakao M. A gel filtration technique for separation of erythrocytes from human blood. f Lab Clin Med 1974;83:840-4.

8 Lapierre Y, Rigal D, Adam J, et al. The gel test: a new way to detect antigen-antibody reactions. Transfusion 1990; 30:109-13.

9 Hitzler W, Shomig-Breckner H, Mathias D. Gel centrifugation test-a new micro method for blood group typing and antibody screening. Arzthide Laboratorium 1989;35: 89-92.

10 Bromilow IM, Adams KE, Hope J, Eggington JA, Duguid JKM. Evaluation of the ID-gel gest for antibody screen- ing and identification. Transfusion Med 1991;1:159-61.

11 de Figueiredo M, Lima M, Morais S, Porto G, Justica B. The gel test: some problems and solutions. Transfusion Med 1992;2:115-8.

12 Salama A, Berghofer H, Mueller-Eckhardt C. Detection of cell-drug (hapten)-antibody complexes by the gel test. Transfusion 1992;32:554-6.

13 Phillips PK, Whitton CM, Lavin F. The use of the antiglobulin 'gel-test' for antibody detection. Transfusion Med 1992;2:111-3.

14 Voak D. Validation of new technology for antibody detection by antiglobulin tests. Transfusion Med 1992;2: 177-9.

15 Poole GD. Evaluation of blood grouping and antibody screening costs. Proceedings of Blood Bank Technology Group. London British Blood Transfusion Society, 1992:7-9. 